\title{
Closing the Gap in Academic Writing Using the Cognitive Load Theory
}

\author{
Imani Akin ${ }^{1}$, Matasha MurrellJones ${ }^{2}$ \\ ${ }^{1}$ American College of Education, USA \\ ${ }^{2}$ Herzing University, USA
}

\begin{abstract}
Explicit instruction for writing is not common within higher education. Student struggles in developing high-quality academic written work occur within the cognitive process and in using scholarly resources. The qualitative study examined existing practices used in supporting student writing in higher education with the purpose of identifying new instructional practices to bridge the gap between thinking and writing. The theoretical framework included the cognitive load theory to examine student needs in terms of short term and long-term cognitive loads. Data was collected from faculty staff and administration of higher education institutions. The significance of the research in higher education includes the development of collective strategies to support the academic writing needs of students and recognition of the role of cognition in student writing challenges. Research to further address thinking and writing and the gap in literature is needed.
\end{abstract}

\section{Introduction}

A lack of synthesis of theory and application in academic writing exist. The deficient directly impacts the quality of academic writing in Higher Education. Students in Higher Education often struggle to create high-quality academic writing. Multiple factors contribute to the gap between theory and application. A gap among the thinking, doing and seeing exists along with the selection of sources to support the writing process. Gaining clarity in the thinking and doing can lead to improvement [10]. Students may rely on non- scholarly resources as opposed to the many facets of scholarly resources available in College and University libraries. The guiding question for the research was: What instructional practices will connect student thinking and writing in Higher Education?

\section{Bridging the Gap in Writing}

Students struggle to produce work demonstrating critical thinking and analysis which aligns with course concepts and materials [11]. The abstract idea is invisible as the student attempts to apply concepts and to demonstrate understanding of content. Bridging the gap between the intellectual processes and developing the written assignment is the focus of study. The space between the idea and the written language is ideal for leveraging processes to lead to high-quality academic writing. Explicit teaching which connects the thinking and writing is not a common process within higher education [22]

\section{Purpose of the Study}

An objective of the research was to examine existing practices as it relates to understanding theory and application in academic writing and identify best practices for developing academic skills to bridge the gap between theory and application in higher education. A qualitative study is appropriate for conducting the research to examine practices to determine how students' approach to writing and synthesis of course content varies based on cognitive approaches and the use of different resources. Previous studies indicate prior knowledge can be the key to student experiences in higher education [16]. The cognitive load theory addresses short and longterm memory in processing new learning and aids in grounding the research.

\section{Review of the Literature}

The review of literature includes research on cognitive learning theory with the purpose of analyzing the cognitive process in preparative for comprehending the writing process. Research includes studies of student writing issues. Barriers to writing were reviewed. Pedagogical strategies for developing curriculum for writing are explored. Instruction and learning strategies were addressed along with methods to encourage bridging the gap in understanding and application of writing strategies.

\subsection{Elements of the Gap in Literature}

Acknowledging a widening diversity of writing experiences contribute to a widening gap in skill level. Research indicates the gap in student writing included knowledge of proper electronic references, planning, evidence, logic and fluency when developing paper assignments [1]. Barriers to writing included lack of time and lack of confidence, and comprehending academic texts or journals [12]. 
Another gap acknowledged prior to the research is the gap between thought and text. Acknowledgement of this space lead to ideas, resources, and tools to bridge this gap. As review of the literature reveals consideration of theory and instruction, thought to the text is not addressed in higher education. Reviewing the research through the lens of the cognitive load theory provides a different approach to developing academic writing skills.

\subsection{Theoretical Framework}

The cognitive load theory addresses short and long-term memory in processing new learning and executing tasks may affect student grasping the logistics of academic writing. The cognition or thinking involved in writing should be sequential. Bridging the gap between theory and application of can occur through pedagogical strategies. Strategic analysis and use of the cognitive load theory requires an understanding of the levels of the theory. Three levels of cognitive load include extraneous, intrinsic, and germane [7]. Presentation of the task addresses the extraneous level. The task difficulty in relation to the individual's expertise connects to the intrinsic level. The student's present level of concentration impacts long term memory and explains the germane level of cognitive load theory. Each level impacts the other to influence the memory. How students think about writing is key to the process of writing.

Table 1. Dimensions of the cognitive theory load

\begin{tabular}{|r|c|c|}
\hline \multicolumn{3}{|c|}{ Cognitive Theory Load - Three levels } \\
\hline Extraneous & $\begin{array}{c}\text { Presentation of the } \\
\text { task }\end{array}$ & $\begin{array}{c}\text { Instructor } \\
\text { Obligation }\end{array}$ \\
\hline Intrinsic & $\begin{array}{c}\text { Task difficulty in } \\
\text { relation to the } \\
\text { individual's expertise }\end{array}$ & $\begin{array}{c}\text { Instructor- } \\
\text { Student Co- } \\
\text { Obligation }\end{array}$ \\
\hline Germane & $\begin{array}{c}\text { Student's present } \\
\text { level of concentration }\end{array}$ & $\begin{array}{c}\text { Student } \\
\text { Obligation }\end{array}$ \\
\hline
\end{tabular}

Cognitive Load theory assesses the mental effort used in the working memory. The emphasis is on lightening the load of the learner allowing information and activities in the classroom directly assist with student learning. It is suggested to not overload the memory. Consciously we can only process a few items at a time for a few seconds [16]. It is important to be intentional about what items are processed over a specified period of time. Additional information offered to students for learning should frame learning directly. Instructors can tap into the prior knowledge of the student prior to adding additional information.

Retrieving old information and adding to working memory will assist with building on what the students already know [2]. Cognitive Load theory began with the notion of students learning to solve problems by practicing on problem solving [21]. Students are able to practice problem solving skills in order to hone the skills needed to examine problems and solve them effectively. As students increase problem solving skills, problem solving has been shown as a great learning tool when applying the cognitive load theory [21].

Intrinsic load describes the load of the learning materials based on complexity. The interactivity of the information processed assists with the determination of the load. Intrinsic load is used to process and comprehend material. Necessary information must be provided to avoid exceeding memory capacity through providing adequate information [13]. This load is required for learning as well as remembering and should be viewed from the perspective of the learner.

Extraneous load controls areas which are not learning based. For example, the use of memory capacity for redundant information the brain will seek and reuse. Reducing the extraneous load assists with avoiding exceeding the memory capacity for redundant information and tasks. Commonly referred to as the bad load because the information is not directly related to learning [13]. This information from this does not directly impact learning as it does not contribute to retention of information and practices.

Germane cognitive load addresses the need for a cognitive level for memory consumption. This cognitive level should be increased in order to augment learning. This is referred to as the good load because the load contributes to schema attainment [13]. The information from the germane cognitive load is transferred to the long-term memory.

\subsection{Curriculum Changes}

Consideration of the learning and thinking processes related to the cognitive load theory when developing curriculum can support the integration of strategies for bridging the gap for writing. Providing multiple steps for developing the writing assignments can support students' development of academic papers. [7] Grangelia, et al, posit instruction designed in this manner aids in reducing the extraneous load. Consequences for not identifying and addressing the gaps through theoretical models are repeated courses for the students and prolonged program completion rates for institutions. Integrating critical thinking into the presentation of the task, aligned with the student's present level of understanding and cognitive ability can support the writing process. 


\section{Method}

A qualitative study was used to conduct research to gather the lived experiences of higher education instructors. The phenomenon of student challenges in academic writing was explored and strategies examined in a pilot study. An examination of best practices to determine how students' approach to writing and synthesis of course content varies. The examination began with a survey of higher education faculty who teach courses with writing assignments. An electronic survey was designed and the link to the survey sent to online and onsite faculty and staff in higher education. The sample population of respondents consisted of higher education faculty and instructors in various grade levels and settings.

The data was collected and analyzed. The data was examined and for an initial review of responses. A deeper analysis of the responses called for locating patterns of language. Themes emerged and were coded and organized. a deeper analysis included a review of all aspects of the respondent; experience. A commonality among the themes was the next phase of analysis and coding. Coding the themes avoided bias. For reliability, the themes were not changed to fit into categories

\section{Findings}

Demographic data was collected from higher education faculty. The respondents were asked about the number of years teaching in higher education and $33.33 \%$ of respondents indicated teaching for 5 years of less. $33.33 \%$ for $5-10$ years. $25 \%$ for $11-15$ years, and $8.33 \%$ have been teaching for more than 16 years.

The content areas taught by respondents varied. Content areas included Education, Educational Leadership, Business, Human Resources, Legal, Marketing, Leadership, Information Technology, Theology, Writing, and Curriculum and Instruction.

Other demographic information included the grade level of population the instructors taught. $33.33 \%$ of respondents teach at the undergraduate level, $41.67 \%$ teach at the graduate level and $25 \%$ teach at the Doctoral level.

\subsection{Resources and Strategies for Writing}

Respondents teach for colleges and universities in which there are many resources available to assist students, including APA and writing resources in the college library, Writing Centers, Tutors \& Coaches. In addition, there are videos, APA sample papers and writing classes available to further assist students in the area of writing. The respondents shared a variety of resources available to assist students with writing at the institutional level. The resources shared by the respondents included Tutoring \& Writing Center,
APA and Writing Center, APA sample papers, Grammarly, Graduate Assistants, Student Coach, Library, Academic Success Center, Write-Point, Center for Writing Excellence, Break out writing classes and videos.

The respondents shared the same general concerns as it relates to student writing. Answers to the survey reveal students struggle with basic writing mechanics and grammar, APA formatting, and Plagiarism. The data indicates students are struggling to meet the requirements of writing assignments. Responses indicate students are not comprehending the assignment instructions and use of rubric. Resources and instances such as instructor provided feedback is not applied by students in order to improve on writing future assignments.

Table 2. Survey Question 5 Responses

Q5. What types of gaps in writing do you see in your classroom or school?

P1 - Not addressing the content properly

P2 - Sentence structure, paragraph structure, citation P3 - The level of scholarly writing to meet graduate level standards

\section{P4 - APA, proper grammar, lexicon}

P5 - Grammar and understanding plagiarism

P6 - Students come in at various levels. Some know APA,

some do not. Some students come in with impeccable

writing while others cannot keep subjectverb agreement

\section{P7 - Lack of primary resources}

P8 - I have noted that students that are ESL struggle more with writing and comprehension of assignment instructions. ...student do not use comments and feedback on assignments to make improvements in writing

\section{P9 - lack of primary resources}

P10 - Inability to construct a cohesive paper that is logically constructed and adheres to the rubric 


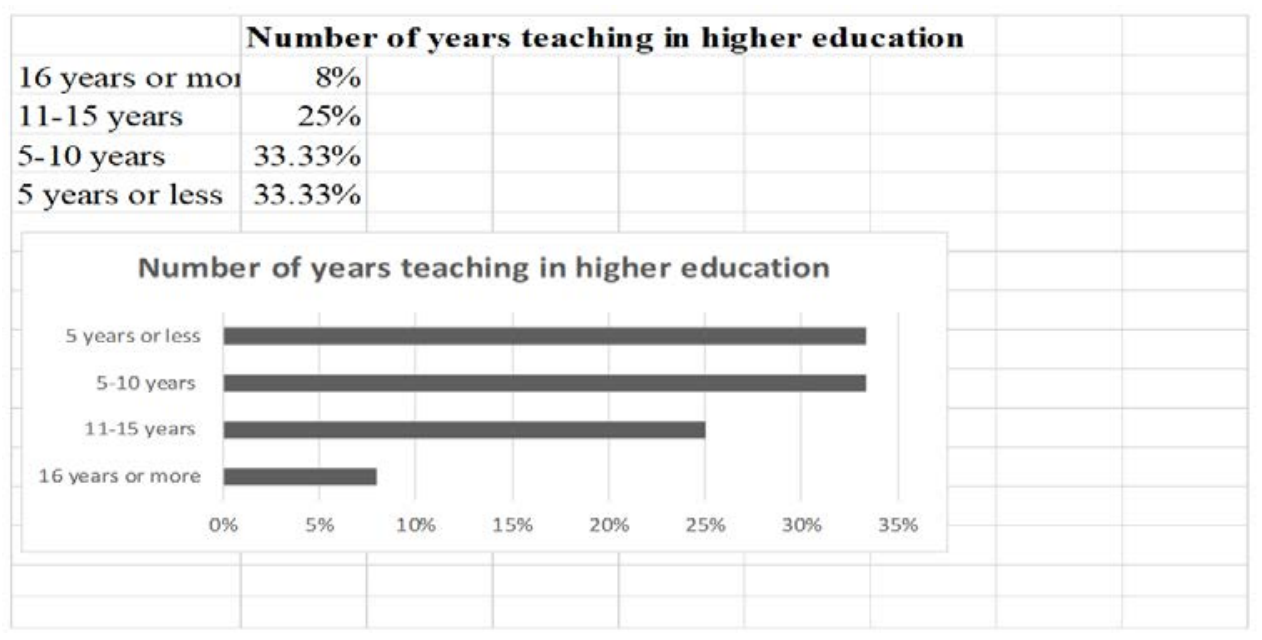

Figure 1. Writing instructor's years of teaching

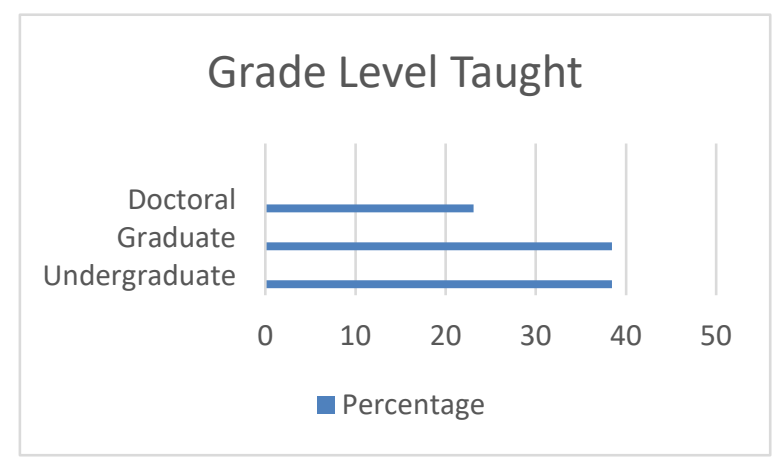

Figure 2. Instructor's grade level taught

\subsection{Monitoring Student Progress}

As it relates to monitoring student progress, Instructors shared how well students responded to feedback, i.e., looking at the major issues within the first written submission and comparing from week to week to identify changes. The quality of student content, attention to details such as citing authors properly, including the manner of structuring assignments with appropriate headings and subheadings is monitored. Monitoring how students connect the introduction and conclusion, and student sense of focus to avoid getting "into the weeds" or "off track" within the writing presentation emerged from the responses.

When asked how instructors assess student progress in closing the gap in academic writing, respondents shared a variety of responses the common themes included the use of rubrics, summative feedback, Instructors allowing students to submit a rough draft prior to submitting the final written assignment. Progress monitoring is used for assessment and other personal techniques such as monitoring the ability of students to construct effective arguments. The introduction of an additional reflection assignment may be used to develop a final draft for an assignment. The assignment can also assist with monitoring student writing improvement over the course of the term.

As it relates to closing the gap in student writing the respondents shared a variety of best practices and ideas to support students in writing effectiveness. The respondents shared the importance of ensuring the common objectives were outlined and measured on a continuous basis. For example, the use of drafts and final drafts. In addition, respondents share the use of pre-and posttests to assess student progress and learning in a holistic approach to writing and critical thinking over several weeks. One on one work with individual students was suggested as students come into courses at various levels and skillsets.

\section{Improving Student Writing}

Student writing does not necessarily reflect the quality of the learner [8]. The learner may have welldeveloped thoughts however, are unable to communicate those thoughts effectively in writing. Developing writing from a critical thinking 
Table 4. Survey Question 9 Responses

Q9. How do you assess student progress in closing the gap in academic writing?

P1 - Define a set of common objectives and then measure progress toward the achievement of this objective related to academic writing. Pre- and post-test (assess the student at the beginning of the course and at the end of the course "this should be a regular and continuous effort" and a holistic approach at the beginning of the "Capstone"

P2 - Review previous assignments to make a comparison

P3 - Examples, feedback

P4 - By using a detailed rubric that has a specific writing component

P5 - Evaluating and watching for improvements in work

P6 - Continue working directly with students

P7 - Each student comes in at various levels. In the course I teach I often I get to see how one document progresses from week 5 to week 10. From my weekly review during this time I see the progress and development in academic writing. My assessment is based on the response to the prompts and guidelines, the thoroughness in writing, the writing style, and how well students learn APA as students develop. Each student needs support in different levels and you must take it as a case by case situation to truly help a student.

P8-Student progress is assessed through summative feedback. Examples are provided to show progress and improvement of student.

P9 - Rubrics first and final drafts (growth)

P10 - Measure progress over the term to see if student is responding to various interventions. If yes, it should be borne out in improved writing as well as content delivery

P11 - Aggregate and individual scores from rubrics, individual and group discussions, vertical curriculum discussions with teachers, review of teacher grade sheets and progress reports

P12 - How well they respond to feedback, i.e., looking at the major issues within the first written submission and comparing from week to week to see how they changed their ways; The quality of the content, the attention to details such as citing authors properly, and the student's ability to construct effective arguments including the manner in which they structure the assignments with appropriate headings and subheadings, how they connect the introduction and conclusion, and how they stay on target and avoid getting "into the weeds" or "off track" within the presentation
Table 5. Survey Question 6 Responses

Q7. What types of resources are you using in the classroom or school to support student learning in the online learning environment?

a Samples of written assignments and promote the writing center.

a Use of writing center and referrals

口 Templates, web resources

\ The institution's writing center support, writing resources online, and my own created ones

a Mentioned above, same as institutional level

- Examples, outside resources for writing, and use of student success center

- The first resource is me and the feedback that I provide to my students on how to improve writing, what they need to work on. If I see they are not improving or not trying to adjust, I send them to the writing center at the college

- I refer student to the Academic Coach for additional support in writing. I also post various informational videos that support writing concepts

- Owl Purdue EBSCO

a Offer on campus support to the online community

- Online writing center, APA formatted Word template, Mendeley

a Providing exemplars with cue boxes, breaking out directions into small steps, helping students recognize own mistakes with writing charts, explaining directions via videos, answering threads with students, instructing mini writing lessons as needed, giving very specific feedback on homework/threads and telling how to correct mistakes, frontloading writing instruction by integrating skills in thread prompts and reinforcing same in assigned essays, grading with the writing rubric, evaluating student writing with my teachers, teaching teachers how to write, etc.

- 1. Directing students to the internal resources available (See \#4 above); 2. Strongly recommending purchase of the Gregg Manual and the APA Manual 6th edition for students' personal libraries and ongoing use; 3. Ensuring students download the Sample APA Paper and Writing Guide from the Student Resources within the Center for Writing Excellence and directing or referring students to specific sections where they appear to need additional attention or work; 4. The Center for Writing Excellence, the online Plagiarism Checker, and the Spellcheck and Grammar checkers they have 
embedded within MSWord; 5. Outlines I provide to the students to help them with more complex assignments; 6. Actually outlining upcoming assignments with students a week or two before the assignment is due to ensure they have a good idea of how to cross-walk between the Syllabus, the grading rubric, and the outline of the written assignment; 7. Detailed grading rubrics that define expectations for satisfactory and exceptional work.

perspective is a process. Students do not enter higher education as graduates as to build and develop the skills needed to be effective writers [8]. Critical thinking may be described as justifying one's judgment through the analysis of evidence [4].

When creating writing assignments instructors and Curriculum development teams should seek to develop assignments which assist with the development of student writing skills. Critical thinking application in higher education is not prominently addressed in writing assignments. The assignments should reinforce the use of tools which assist students with demonstrating critical thinking and analysis while aligning with course concepts and materials [4].

\subsection{Reflective Writing}

Reflective writing is a practice which can be used to foster critical thinking in students. The student writer describes a particular event or scene adding information from the student's personal reflection of the situation [6]. Requiring students to find different perspectives on issues and dilemmas provides the opportunity for the student to analyze and synthesize information as part of the writing process [17]. Reflective writing encourages thinking as the student learner answers a question from the perspective of practical use to the student [6].

Students begin with addressing the problem. The student must explain the issue or problem in the assignment. Next, the student should reflect on the meaning of the issue or problem. What does it all really mean? From a reflective standpoint the student can place themselves in the shoes of the person in the scenario and reflect on personal thinking or approach to the situation. Why is it student feel and thinks this way? Finally, the student should address the plan of how to proceed differently. The reflection begins as the student begins to answer questions through personal probing. This question process is foundation of reflective writing [6].

\subsection{Two Part Assignments with Post Scripts}

The two-part writing assignment with post script consists of two assignments, the draft and the final submission. This type of assignment is used to engage the student in the writing and critical thinking analysis process in order to assist students with writing better papers [4]. Self-assessment is also used to enhance the student learning experience.

As part of the draft the students are required to submit an assignment addressing a specific question along with specified style requirements. The question cannot be found in the textbook or other course materials requiring the student to engage in critical thinking without being influenced by material discussed in the course [4]. The student will not be able to regurgitate course information. The student will be required to explain an ideology or concept, then apply the specific ideology or concept to a scenario from two perspectives. Finally, in the draft the student will be required to compare the two perspectives [4]. The student is provided extensive feedback to assist them with crafting the final writing submission.

As part of the final submission the students are required to add additional information and insight into the written drafts. Students are required to add outside scholarly resources to the paper. The students should add at least 5 articles supporting personal opinions or challenge the perspectives from the draft. In addition, students are to reflect on the drafts and feedback to enhance the quality of the final written assignment. Both assignments are weighed the same in terms of points. However, the student could earn a lower score on the final submission if the feedback is applied from the draft assignment as well as add the new required information. Students are also required to submit 5 sources for review. Finally, students are required to self-assess in the post script. This selfassessment allows the student to share what was learned.

\subsection{Problem Based Learning}

Problem Based Learning assignments may be used to assist students in learning application through the use of the experience of solving open ended problems. Students are able to engage in personalized learning through the use of reflecting and reasoning when developing a strong solution for the problem. Problem based learning has been used to enhance critical thinking in students [19]. Scenarios are given to students to guide them through understanding the audience and how to evaluate the needs of the audience in an effort to assist with the application of theory from the course objectives and goals.

Instructors who choose to use the Problem-Based Learning approach should create a plan for use. For 
example, instructors should begin with determining the role problem-based learning will play in the course and with the various written assignments in the course. Next, when creating the scenarios, it is important to create rubrics to evaluate student comprehension and writing as well [15]. When creating the scenario, the faculty member should be sure the scenario is one which will require research, critical thinking, and learning to meet the objectives of the week or course. In addition, the scenario should be interesting and motivate the student to learn more. As students work through the scenarios, incentives should be included as part of the writing assignment to not only share how the approach the scenario, but why. Why did the student make this decision and how will it impact the company/parties in the scenario in the long term [14]?

Problem-Based Learning is a great approach for instructors to use as means to allow students to work through a real-life scenario, so students can grasp the real-world application of the course concepts. Students will be able to find more value in what the learning and are able to clearly understand how it is applied in the real world. In addition, if the instructor creates the scenarios and are able to ensure critical thinking, concept application, and learning is evident as students complete the scenarios for the written assignments [23]. The instructor does have a responsibility in assisting students with the critical application of the course material. Instructors should assist the student with critical thinking through guiding the problem-based learning process [18].

Problem based learning requires students to provide focus and attention as it relates to the audience and purpose of the assignment [8]. The problem-based learning approach assists with the development and application of critical thinking as part of written assignments through the use of evaluation techniques. Problem based learning application encourages students to evaluate the audience's needs and developing a purpose for the writing projects. Each problem set up different audiences and purposes for writing-often requiring students to write in a new genre" [15]. Scenarios are given to students to guide them through understanding the audience in which they are writing for and how to evaluate the needs of the audience in an effort to assist with the application of theory from the course objectives and goals.

When seeking to apply the problem-based learning approach lesson guides and planning are required. Determination of the role of the scenarios and projects to student learning and critical thinking application is the first step in the planning process. Rubrics are created to evaluate student comprehension and writing as well. When creating the scenario, the faculty member should be sure the evidence research, critical thinking, and learning meets the objectives of the week or course as part of the scenario. In addition, the scenario should be interesting and motivate the student to learn more. As students work through the scenarios they should be encouraged as part of the writing assignment to not only share how they would approach the scenario, but why. Why did they make this decision and how will it impact the company/parties in the scenario in the long term?

\subsection{Worked Examples}

Worked examples are a step by step approach to demonstrating the expectations for an assignment or project. This approach is a step by step guide to solving a problem or performing a specific task. It provides students with the mental support and direction needed to clearly understand what the end result should look like and how to attack the task [5]. Worked examples may include how the problem is formed, the steps to solving the problem, and the final solution or how the final task should look.

Providing students with worked examples allows the students to understand how the problem is formulated and solved. It allows the student to understand step by step how to tackle the problem and understand the reasoning for the correct response. This allows the students to critically think about the assignments because students can see where the mistakes are and where students have gone wrong or the areas posing difficulty. The student can then review the material or reach out for more guidance. Providing the information in steps also allows for more effective feedback as the feedback can be generated based on each required step in the process.

\section{Implications}

Common themes include encouraging students to use the institutionally supported resources, providing outlines, using outside resources such as Purdue Owl, templates, web resources and instructor feedback to students. In addition, instructor created resources can assist students in the journey to effective writing. Instructor created assignments and rubrics can assist with reaching the various skillsets of the students at beginning of the term at different levels, but are afforded the same opportunity for growth and development over the course of the term.

The examination of current research led to developing new instructional approaches to support the academic writing process. Best practices may involve technology to support instructional delivery of a high-quality academic writing process within the learning management systems, at the University level. Other methods of instructional delivery such as face-to-face communication may be identified and included in the instructional approach to assist students in learning another method to academic 
writing. These curriculum changes can lead to a model and plan of action to raise the quality of student academic writing.

\section{Conclusion}

Discussion of the standards of students' level of academic writing is a global issue [16]. Research on student writing in higher education addresses many ways to approach and consider the issue. Bridging the gap between theory and application to enhance student writing is an approach, which could increase thinking and the quality of writing.

\section{References}

[1] Akin, I., Neumann, C., (2018). Aligning assessment with instruction. In Silverberg, D. Institutional change from within: Teaching and learning in higher education (Chapter 3) Lanham, MD: Rowman and Littlefield Publishers.

[2] Baddeley, A. D., (2003). Working memory: looking back and looking forward. Nature Reviews Neuroscience, 4 (10), 829-839, doi: 10.1038/nrn1201.

[3] Behrens, S.J., Johnson, A., Allard, M., Caroli, A., (2016). I know it when I see it: Uncovering Student and educator expectations about academic writing in higher education, Writing \& Pedagogy, 8(2). doi: 10.1558/wap. 24108.

[4] Çavdar, G., Doe, S., (2012). Learning through writing: teaching critical thinking skills inwriting assignments. PS, Political Science \& Politics, 45(2), 298-306. doi:10.1017/S1049096511002137

[5] Clark, R.C., Nguyen, F. and Sweller, J., (2006). Efficiency in learning: evidence-based guidelines to manage cognitive load. San Francisco: Pfeiffer

[6] Cowan, J., (2014). Noteworthy matters for attention in reflective writing journal writing. Active Learning in Higher Education. 15(1), 53-64, doi:10.1177/ 1469787413514647

[7] de Araujo Guerra Grangeia T, de Jorge B, Franci D, Martins Santos T, Vellutini Setubal MS, Schweller M, et al. (2016) Cognitive load and self- determination theories applied to e-learning: Impact on students' participation and academic performance. PLoS ONE 11(3). doi: 10.1371/journal.pone.0152462

[8] Faragher, L., Huijser, H., (2014). Exploring evidence of higher order thinking skills in the

writing of first year undergraduates. The International Journal of the First Year in Higher Education, 5(2), 33-44. doi: 10.5204/intjfyhe. v5i2.230

[9] Grangelia, T., de Jourge, B., Franci, B., Santos, T. M., Setubal, M., Schweller, M., deCarvalho-Filho, M., (2016) Cognitive load and self-determination theories applied to e-learning; Impact on students' participation and academic performance doi: 10.1371/journal.pone.0152462

[10] Harvey, J., (2008). Bridging the gap: The intellectual and perceptual skills for better academic writing, Teaching Philosophy, 31(2), 151-159. doi:10.5840/teachphil2008 31217.

[11] Hodgson, J., Harris, A., (2012). Improving student writing in higher education: Putting literacy studies to work. English in Education, 46(1), 8-21. doi: 10.1111/j.1754-8845.2011.01112x

[12] Itua, I., Coffey, M., Merryweather, D., Norton, L., Foxcroft, A., (2012). Exploring barriers and solutions to academic writing: Perspectives from students, higher education and further education tutors. Journal of Further and Higher Education, 38(3) 3305-326. doi.org/10.1080/0309877X.2012.726966

[13] Kalyuga, S., (2011). Cognitive load theory: how many types of load does it really need? Edu Psychol Rev, 23, doi: 10.1007/s10648-010-9150-7

[14] Kalyuga, S., Singh, A., (2016). Rethinking the boundaries of cognitive load theory in complex learning. EduPsychol Rev, 28:831-852, doi: 10.1007/s10648-0159352-0.

[15] Kumar, R., (2017). Problem-based learning pedagogy fosters students' critical thinking about writing. Interdisciplinary Journal of Problem-Based Learning. 11(2), doi: 10.7771/1541-5015.1670.

[16] Lea, S. \& Corey, D. (2009). The writing project: 'Bridging the Gap' into undergraduate study, Student Centered Learning. Retrieved from https://www.heacademy.ac.uk/system/files/e3_writin g_project.pdf [Accessed: 17- May- 2017]

[17] Liao \& Wang. (2016). The application of heterogenous cluster grouping of reflective writing for medical humanities literature study to enhance student's empathy, critical thinking, and reflective writing. BMC Medical Education, 16:234, doi: 10.1186/s12909-0160758-2.

[18] Nargundkar, S. (2014). A guided problem-based learning (PBL) approach: impact on critical Thinking. Decision Sciences Journal of Innovative Education, 12(2), 91-108, doi: 10.1111/dsji.12030.

[19] Peach, B. E., Mukherjee, A., \& Hornayak, M. (2007). Assessing critical thinking: A college's journey and lessons learned. Journal of Education for Business, 82(6), 313-320, doi: 10.3200/JOEB.82.6.313-320.

[20] Sceniak, L. (2012). Bridging the gap: Understanding the skills and writing knowledge of entering college composition students. Retrieved from http://trace.tennessee.edu/utk_gradthes/1203/ [Accessed: 20- April- 2017].

[21] Schnotz, W., Kurschner, C., (2007). A reconsideration of cognitive load theory. Edu Psychol Rev, 19 (1), doi:10.1007/s10648-007-9053-4. 
[22] Van de Poel, K. Brunfaut, T., (2004). Bridging the gap between staff expectations and student interpretations of academic writing: the case of Scribende, 2(7) Belgian Journal of English Language and Literatures, 2, 329335.Retrieved from http://www.baahe.be/bell/bell.htm [Accessed: 17- May- 2017].

[23] Xiao-Wei, D., (2016). The effect of wechat-assisted problem-based learning on the critical thinking disposition of the ELF learners. International Journal of Emerging Technologies in Learning, 11(12), 23-29, doi: 10.3991/ijet.v11i12.5927. 